\title{
Choice of anesthetic technique on plasma concentrations of interleukins and cell adhesion molecules
}

Daniela C lonescu ${ }^{1,2^{*}}$, Simona Claudia D Margarit ${ }^{1}$, Adina Norica I Hadade ${ }^{3}$, Teodora N Mocan ${ }^{4}$, Nicolae A Miron ${ }^{5}$ and Daniel I Sessler ${ }^{6}$

\begin{abstract}
Background: Whether inflammatory responses to surgery are comparably activated during total intravenous anesthesia (TIVA) and during volatile anesthesia remains unclear. We thus compared the perioperative effects of TIVA and isoflurane anesthesia on plasma concentrations of proinflammatory and anti-inflammatory interleukins and cell adhesion molecules.

Methods: Patients having laparoscopic cholecystectomies were randomly allocated to two groups: 44 were assigned to TIVA and 44 to isoflurane anesthesia. IL-1 $\beta, I L-6, I L-8, I L-10, I L-13$, and the cellular adhesion molecules intercellular adhesion molecule-1 and vascular cell adhesion molecule-1 were determined preoperatively, before incision, and at 2 and 24 hours postoperatively. Our primary outcomes were area-under-the-curve cytokine and adhesion molecule concentrations over 24 postoperative hours.
\end{abstract}

Results: The only statistically significant difference in area-under-the-curve concentrations was for IL-6, which was greater in patients given isoflurane:78 (95\% confidence interval (Cl): 52 to 109) pg/ml versus 33 (22 to 50) pg/ml, $P=0.006$. Two hours after surgery, IL- 6 was significantly greater than baseline in patients assigned to isoflurane: 47 (95\% Cl: 4 to $216, P<0.001) \mathrm{pg} / \mathrm{ml}$ versus 18 (95\%Cl: 4 to $374, P<0.001) \mathrm{pg} / \mathrm{ml}$ in the TIVA group. In contrast, IL-10 was significantly greater in patients assigned to TIVA: 20 (95\% Cl: 2 to $140, P<0.001) \mathrm{pg} / \mathrm{ml}$ versus 12 (95\% Cl: 3 to $126, P<0.001) \mathrm{pg} / \mathrm{ml}$. By 24 hours after surgery, concentrations were generally similar between study groups and similar to baseline values.

Conclusion: The only biomarker whose postoperative area-under-the-curve concentrations differed significantly as a function of anesthetic management was IL-6. Two hours after surgery, IL-6 concentrations were significantly greater in patients given isoflurane than TIVA. However, the differences were modest and seem unlikely to prove clinically important. Further studies are needed.

Keywords: Inhalation anesthetics, Intravenous anesthetics, Propofol, Cell adhesion molecules, Interleukins

\section{Background}

Surgery provokes hemodynamic, metabolic, and inflammatory responses; it also provokes a complex immune reaction [1] that includes activation of the interleukin network [2]. For example, surgery and anesthesia provoke an increase in proinflammatory interleukins and adhesion

\footnotetext{
* Correspondence: dionescuati@yahoo.com

'Department of Anesthesia and Intensive Care I, 'Iuliu Hatieganu' University

of Medicine and Pharmacy, Croitorilor, nr. 19-21, Cluj-Napoca 400162, Romania

${ }^{2}$ Outcomes Research Consortium, Cleveland, OH, USA

Full list of author information is available at the end of the article
}

molecules, and a subsequent increase in countervailing anti-inflammatory interleukins [3-5]. The most important proinflammatory interleukin is IL-6, while the most potent anti-inflammatory interleukin is IL-10.

Cell adhesion molecules (CAMs) are members of the immunoglobulin family and are regulated by the inflammatory interleukins [6]. CAMs promote wound healing $[7,8]$ and can also promote tumor progression and metastasis $[9,10]$, either directly or by promoting overproduction of inflammatory interleukins. The mechanisms of action differ for intercellular adhesion molecule
C Biomed Central

(c) 2013 lonescu et al.; licensee BioMed Central Ltd. This is an Open Access article distributed under the terms of the Creative Commons Attribution License (http://creativecommons.org/licenses/by/2.0), which permits unrestricted use, distribution, and reproduction in any medium, provided the original work is properly cited. 
(ICAM)-1 and vascular cell adhesion molecule (VCAM)-1. ICAM-1 produces its effects by promoting recruitment and adhesion of leukocytes to the activated endothelium via bonds with integrins, thus promoting migration through endothelial cells [11]; VCAM-1, produced mainly by the endothelial cells after interleukinmediated stimulation, promotes adhesion of inflammatory cells to the vascular wall and subsequent migration [12]. Reduced plasma ICAM-1 concentration may facilitate tumor cell movement across vessels into surrounding tissues, thus promoting metastasis. Some tumor cells may also use VCAM-1 to adhere to the vascular walls and to migrate $[13,14]$. CAMs are influenced by the surgery [15] and may influence outcome after oncological surgery [14-17].

The two major approaches to general anesthesia are volatile anesthetics such as isoflurane and intravenous anesthesia such as propofol. General anesthesia may impair immune function directly by affecting immunocompetent cells such as natural killer (NK) cells and macrophages, cytokine responses, and adhesion molecules. Alternatively, anesthesia may indirectly influence the stress response to surgery $[1,5,18,19]$.

There appear to be substantial differences between intravenous and volatile anesthetics in their effects on various immune functions [20-22]. While isoflurane inhibits interferon stimulation of NK cell cytotoxicity and sevoflurane alters the release of cytokines by NK, propofol does not significantly suppress NK cell activity [19]. Propofol alone increased apoptosis and cell adhesion and did not significantly influenced cell migration in breast cancer cells, while propofol conjugates significantly increased apoptosis and decreased migration and adhesion in breast cancer cells [23]. Propofol down-regulates proinflammatory interleukins [24,25]. Although some studies suggest that total intravenous anesthesia (TIVA) suppresses inflammatory responses and promotes release of anti-inflammatory cytokines $[18,20,21]$, the reported results are inconsistent [26]. The few studies that evaluated the effects of anesthesia on cellular adhesion molecules report that both inhalation agents and propofol blunt the increase in ICAM and VCAM expression [27,28]. Whether interleukins and other inflammatory molecules are comparably activated during TIVA and volatile anesthesia thus remains unclear.

Our study was designed to compare the effects of TIVA and volatile anesthesia on plasma concentrations of proinflammatory and anti-inflammatory interleukins and on CAMs during laparoscopic surgery. Specifically, we tested the hypothesis that TIVA blunts the inflammatory response to laparoscopic cholecystectomy more than isoflurane anesthesia. Laparoscopic surgery was chosen because the amount of tissue injury is small and similar from case to case, thus reducing the impact of surgery per se on immune responses.

\section{Methods}

After obtaining university Ethics Committee approval (Comisia de Etica a Universitatii de Medicina si Famacie 'Iuliu Hatieganu', Cluj-Napoca, No. 178A/2007) and written informed consent, we enrolled 88 patients with American Society of Anesthesiologists physical status scores 1 or 2 who were scheduled for laparoscopic cholecystectomy. We excluded patients with known inflammatory diseases (including acute cholecystitis) or immune system disorders, asthma, obesity (body mass index $\geq 30 \mathrm{~kg} / \mathrm{m}^{2}$ ), diabetes, gastric ulcers, and allergies. We also excluded patients who currently or recently used steroid or anti-inflammatory medication, or who had white blood cell counts $>10^{4} / \mu$ l or a preoperative core temperature $>37^{\circ} \mathrm{C}$.

\section{Protocol}

Midazolam, $7.5 \mathrm{mg}$ orally, was given 1 hour before surgery. Dexamethasone, $4 \mathrm{mg}$ intravenously, was given shortly before induction of anesthesia as prophylaxis against postoperative nausea and vomiting [29]. Then $500 \mathrm{ml}$ crystalloid was infused during anesthetic induction, and thereafter as clinically indicated.

Patients were randomized into two study groups using a computer-generated sequence: one-half were assigned to target-controlled infusion TIVA with propofol, and one-half to isoflurane volatile anesthesia. Allocation was concealed in sequentially numbered sealed envelopes, with assignments revealed when patients were arriving in the operating theater. Laboratory staff were blinded to group assignments and anesthetic management.

TIVA was induced and maintained with a targetcontrolled infusion of propofol with an initial target plasma concentration of $4 \mu \mathrm{g} / \mathrm{ml}$ (Orchestra, Base Primea; Fresenius Kabi, Fresenius Vial SAS, Brézins, France). The propofol infusion was adjusted to target a Bispectral Index between 40 and 55 (Covidien, Dublin, Ireland). Isoflurane anesthesia was induced with propofol 1.5 to $2 \mathrm{mg} / \mathrm{kg}$ and maintained with isoflurane 1 to 1.5 minimum alveolar concentration titrated to Bispectral Index 40 to 55 and hemodynamic parameters.

Patients were ventilated with $70 \%$ oxygen in air and a positive end-expiratory pressure of 3 to $4 \mathrm{cmH}_{2} \mathrm{O}$. The respiratory rate and inspiratory pressure were adjusted to maintain an end-tidal carbon dioxide partial pressure of 35 to $45 \mathrm{mmHg}$ (Drager-Vamos, Lubeck, Germany). Remifentanil was infused under manual control with an initial dose of $0.5 \mu \mathrm{g} / \mathrm{kg} /$ minute in the first minute and $0.25 \mu \mathrm{g} / \mathrm{kg} /$ minute thereafter; the remifentanil dose was adjusted in 0.05 to $\mu \mathrm{g} / \mathrm{kg} /$ minute increments as clinically necessary. Atracurium $0.6 \mathrm{mg} / \mathrm{kg}$ was initially given to provide paralysis for intubation; subsequently, $10 \mathrm{mg}$ boluses were given as clinically needed. Hypotension 
(defined as a decrease in blood pressure $>30 \%$ from baseline) was corrected with additional fluids and/or ephedrine. At the end of surgery, anesthesia was discontinued and muscle relaxation antagonized with neostigmine and atropine.

Postoperative analgesia was provided by oral paracetamol $1 \mathrm{~g}$ every 8 hours and intravenous meperidine 0.3 to $0.4 \mathrm{mg} / \mathrm{kg}$ upon patient request or when verbal response pain scores exceeded 3 (on a 5 -point scale with $0=$ no pain and $5=$ worst pain possible). Nonsteroidal agents (nonsteroidal anti-inflammatory drugs) were not given. Metoclopramide, $10 \mathrm{mg}$ intravenously, was the initial treatment for postoperative nausea and vomiting; $4 \mathrm{mg}$ ondansetron was added if necessary.

\section{Measurements}

Routine anesthetic monitoring was used as recommended by the American Society of Anesthesiologists.

Venous blood $(7 \mathrm{ml})$ was sampled immediately after inserting the first peripheral cannula (T1), after intubation but before incision (T2), 2 hours after emergence (T3) and 24 hours (T4) after anesthesia. Samples were collected and centrifuged at 2,500 $\times g$ for 10 minutes at room temperature; the resulting 3 to $4 \mathrm{ml}$ plasma samples were stored at less than $-20^{\circ} \mathrm{C}$ until assayed.

Plasma concentrations of interleukins and the CAMs soluble ICAM-1 and soluble VCAM-1 were measured by an ELISA technique using commercially available kits (Quantikine; R\&D Systems, Minneapolis, MN, USA) as per the manufacturer's instructions. Laboratory staff were unaware of study groups and were not involved in anesthetic management.

Detection limits for interleukins as given by the manufacturer were as follows: IL-1, typically $<1 \mathrm{pg} / \mathrm{ml}$; IL-6, $<0.7 \mathrm{pg} / \mathrm{ml}$; IL-8, $<1.5 \mathrm{pg} / \mathrm{ml}$; IL-10, $<3.9 \mathrm{pg} / \mathrm{ml}$; and IL-13 ,$<32 \mathrm{pg} / \mathrm{ml}$. Intra-assay and inter-assay coefficients of variation were both $<10 \%$. The detection limits for soluble VCAM-1 ranged from 0.2 to 1.3 (mean $=0.6) \mathrm{ng} / \mathrm{ml}$ and the limits for soluble ICAM-1 ranged from 0.05 to $0.25($ mean $=0.10) \mathrm{ng} / \mathrm{ml}$, with intra-assay and interassay variation coefficients both $<8 \%$ (Quantikine; R\&D Systems).

Normal plasma concentrations of interleukins, as given by the manufacturer, are: IL- $1 \beta, 1$ to $4 \mathrm{pg} / \mathrm{ml}$; IL- 6 , 0.7 to $12 \mathrm{pg} / \mathrm{ml}$; IL-8,4to $31 \mathrm{pg} / \mathrm{ml}$; IL-13,32 to $62 \mathrm{pg} / \mathrm{ml}$; and IL-10,4 to $8 \mathrm{pg} / \mathrm{ml}$. Normal plasma concentrations of CAMs, as given by the manufacturer, are 349 to 991 $\mathrm{ng} / \mathrm{ml}$ for soluble VCAM-1 and 99 to $320 \mathrm{ng} / \mathrm{ml}$ for soluble ICAM-1.

\section{Statistical analysis}

Sample size was estimated from a pilot study with 22 patients per group. Calculated area-under-the-curve (AUC) values for IL-6 showed a $46 \mathrm{pg}$.hour/ml difference between the two groups (standard deviation $=60$ and 62, respectively). Using a two-tailed $\alpha$ error of 0.01 , we estimated that 41 patients per group would provide an $80 \%$ power. Anticipating some inadequate samples, we enrolled 44 patients in each study group.

Chi-square tests were used to assess correlations between dichotomous data. The distribution for continuous data was evaluated using the Kolmogorov-Smirnov test, with subsequent comparison by $t$ test or MannWhitney $U$ test as appropriate. AUC values over 24 hours and values at each measurement time were determined in individual patients using the preoperative concentration as the baseline; between-group AUC differences were subsequently determined using MannWhitney U tests.

Data are expressed as either mean \pm standard deviation or median (95\% confidence interval (CI)). Post-hoc comparisons with baseline values of biomarker concentrations recorded at two different postoperative time intervals were performed using the Wilcoxon test. A Bonferroni correction was used with a consequent reduction of the $\alpha$ threshold to 0.01 .

Data analyses were performed using SPSS 17.0 (SPSS Inc., Chicago, IL, USA) and Medcalc 8.3.1.1 (MedCalc Software, Mariakerke, Belgium) statistical packages.

\section{Results}

Ninety-one patients were enrolled in the study and were randomized ( 46 to isoflurane and 45 to TIVA). Three patients were excluded from analysis because they were discharged within 24 hours or acute inflammation of the gallbladder was identified intraoperatively; we thus present data from the remaining 88 patients (44 per group) who completed the study. Demographic data were similar in each anesthetic group, as were anesthetic and surgical management (Table 1).

Propofol targeted plasma concentrations in the targetcontrolled infusion TIVA group averaged $2.4 \pm 0.5 \mu \mathrm{g} /$ $\mathrm{ml}$. The mean end-tidal isoflurane level in patients assigned to volatile anesthesia was $1.1 \pm 0.3 \%$.

None of the patients became hypothermic during operation. The mean intraoperative temperature was $36.6 \pm 0.2^{\circ} \mathrm{C}$.

Pre-induction plasma cytokine and adhesion molecule concentrations were similar in the two study groups (Table 2).

Plasma concentrations for IL-1 $\beta$, IL-6, IL-8, IL-10, IL-13, soluble ICAM-1, and soluble VCAM-1are shown in Figures 1, 2, 3, 4, 5, 6, and 7, respectively. The largest cytokine responses to surgery were observed for IL-6 and IL-10, each with significant peak concentrations 2 hours after surgery. IL- 6 was significantly greater in patients assigned to isoflurane: 46.4 (95\% CI: 34.3 to 70.7 ) pg/ml versus 17.6 (95\% CI: 11.9 
Table 1 Demographic data of the study groups

\begin{tabular}{|c|c|c|c|}
\hline & Total intravenous anesthesia $(n=44)$ & Isoflurane $(n=44)$ & $P$ value \\
\hline Age (years) & $52 \pm 12$ & $46 \pm 14$ & 0.19 \\
\hline Weight (kg) & $74 \pm 16$ & $75 \pm 16$ & 0.72 \\
\hline Gender (female/male) & $34 / 10$ & $38 / 6$ & 0.40 \\
\hline American Society of Anesthesiologists I/II & $20 / 24$ & $25 / 19$ & 0.39 \\
\hline Anesthesia time (minutes) & $54 \pm 15$ & $54 \pm 14$ & 0.90 \\
\hline Intraoperative Bispectral Index & $43 \pm 4$ & $44 \pm 4$ & 0.22 \\
\hline Intraoperative mean arterial pressure $(\mathrm{mmHg})$ & $84 \pm 17$ & $78 \pm 16$ & 0.07 \\
\hline Intraoperative heart rate (beats/minute) & $76 \pm 14$ & $74 \pm 14$ & 0.44 \\
\hline Intraoperative core temperature $\left({ }^{\circ} \mathrm{C}\right)$ & $36.5 \pm 0.3$ & $36.6 \pm 0.3$ & 0.13 \\
\hline Intraoperative intravenous fluids (I) & $1.2 \pm 0.2$ & $1.3 \pm 0.2$ & 0.47 \\
\hline Intraoperative remifentanil ( $\mu \mathrm{g} / \mathrm{kg} /$ minute) & $0.3 \pm 0.06$ & $0.3 \pm 0.05$ & 1.00 \\
\hline
\end{tabular}

Data expressed as mean \pm standard deviation or number of patients.

to 20.7$) \mathrm{pg} / \mathrm{ml}(P<0.01)$. In contrast IL-10 was greater in patients assigned to TIVA: 20.1 (95\% CI:14.2 to 32.4) $\mathrm{pg} / \mathrm{ml}$ versus $12.4(95 \% \mathrm{CI}: 8.8$ to 18.7$) \mathrm{pg} / \mathrm{ml}$ $(P=0.03)$. By 24 hours after surgery, concentrations were similar in each group and similar to baseline values, except for IL-6 that remained significantly increased in both groups $(P<0.001)$ and for IL-10 that remained significantly increased in patients given isoflurane $(P=0.009)$. IL-4 concentrations were below the detection limits of our assay at all times and are therefore not reported.

Between-group comparisons of the cytokine plasma concentration AUC for every measured parameter in the study groups are showed in Table 3; the only significant difference was for IL-6 $(P=0.006)$, with values being greater in patients assigned to isoflurane anesthesia.

\section{Discussion}

The possibility that anesthetic management influences long-term outcomes in surgical patients is intriguing, but remains largely speculative. Nonetheless, there is

Table 2 Pre-induction interleukin and cell adhesion molecules plasma concentrations

\begin{tabular}{|c|c|c|}
\hline & $\begin{array}{l}\text { Total intravenous } \\
\text { anesthesia }(n=44)\end{array}$ & Isoflurane $(n=44)$ \\
\hline$\|-1 \beta(p g / m l)$ & $1.0(1.02$ to 1.18$)$ & $1.0(0.99$ to 1.31$)$ \\
\hline IL-6 (pg/ml) & 3.4 ( 2.6 to 5.5$)$ & $2.2(1.2$ to 2.7$)$ \\
\hline IL-8 (pg/ml) & 19.3 (12.4 to 34.6) & 16.7 (12.1 to 24.0$)$ \\
\hline IL-10 (pg/ml) & 6.1 (5.1 to 6.9$)$ & 4.8 (4.1 to 6.0$)$ \\
\hline IL-13 (pg/ml) & 30.6 (27.2 to 34.0$)$ & 33.7 (28.8 to 35.8 ) \\
\hline $\begin{array}{l}\text { Soluble ICAM-1 } \\
(\mathrm{ng} / \mathrm{ml})\end{array}$ & 69.0 (65.2 to 76.6) & 66.1 (60.74 to 74.7$)$ \\
\hline $\begin{array}{l}\text { Soluble VCAM-1 } \\
(\mathrm{ng} / \mathrm{ml})\end{array}$ & 383 (349.03 to 408) & 362 (335 to 402) \\
\hline
\end{tabular}

Data expressed as median ( $95 \%$ confidence interval). ICAM, intracellular adhesion molecule; VCAM, vascular cell adhesion molecule. limited (and often controversial) evidence - or at least plausible mechanisms - to suggest that anesthetic management might influence diverse outcomes including wound infection [30-32], major cardiac complications and strokes [33], brain development [34], cancer recurrence [35-37], and mortality [30,38]. Because the inflammatory response to surgery seems likely to be an important potential mechanism, and possibly even a common pathway for many outcomes, we evaluated the cytokine responses in patients randomly assigned to TIVA or volatile anesthesia.

Based on our primary AUC analysis, the only cytokine that differed significantly as a function of anesthetic approach was IL-6, and the increase was only marginally statistically significant $(P=0.006$ with an $\alpha$ threshold of 0.01 because of multiple comparisons). Furthermore, the factor of two increase - which is small by the standards of cytokines - seems unlikely to be clinically important. Judging by cytokine responses, our results thus suggest that the choice of TIVA versus volatile anesthesia only slightly alters the inflammatory response to surgery.

Within-group comparisons showed that IL-6 increased significantly at 2 hours postoperatively in both groups, but that the increase was significantly greater in patients assigned to isoflurane anesthesia. IL-10 was also significantly increased in both groups after 2 postoperative hours, but with greater plasma concentrations in patients given TIVA [3]. At 24 hours postoperatively, IL-6 remained increased in both study groups while IL-10 remained increased only in the inhalation group, probably to counteract the increase in IL-6; however, the increases were marginal.

Our results are generally consistent with previous reports by Ke and colleagues, Gililand and colleagues, and Crozier and colleagues [20-22]. For example, Ke and colleagues reported similar responses for IL-6 and IL-10 during laparoscopic cholecystectomy. Results reported 


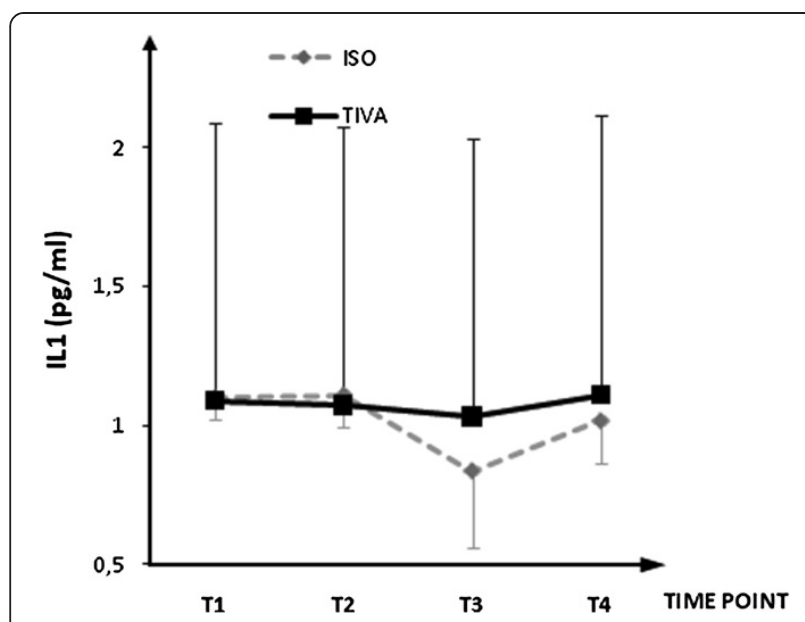

Figure 1 Plasma IL-1 $\boldsymbol{\beta}$ concentrations. Data expressed as median (95\% confidence interval). T1 = before induction; T2 = immediately after induction; T3 = at 2 hours after skin closure; T4 = at 24 hours after skin closure. Area under the curve: isoflurane $(\mathrm{ISO})=3.3$, total intravenous anesthesia (TIVA) $=3.4 . P=0.428$.

by Gililand and colleagues in abdominal surgery and by Crozier and colleagues after abdominal hysterectomy were also generally similar. In contrast, Helmy and colleagues reported that IL-6 does not increase after laparoscopic cholecystectomy [39]. Potential explanations include use of a different kit for interleukin assays and variations in surgical technique.

Although there were differences in anesthetic protocols and type of surgery, Deegan and coworkers observed IL-10, IL-8, and IL-13 responses similar to ours when propofol and paravertebral anesthesia was compared with volatile

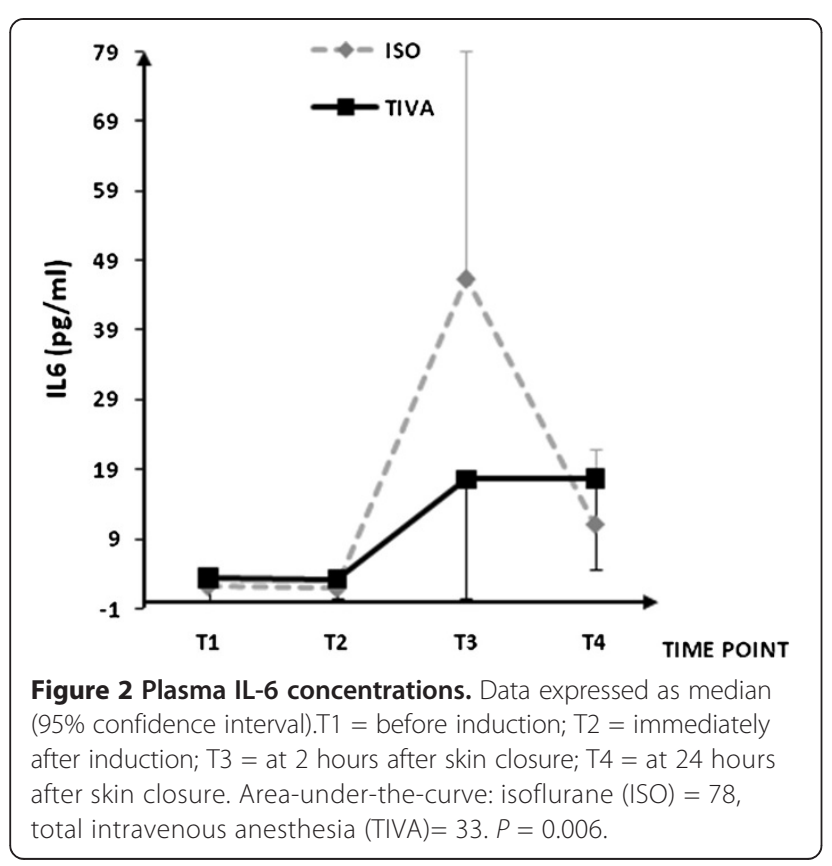

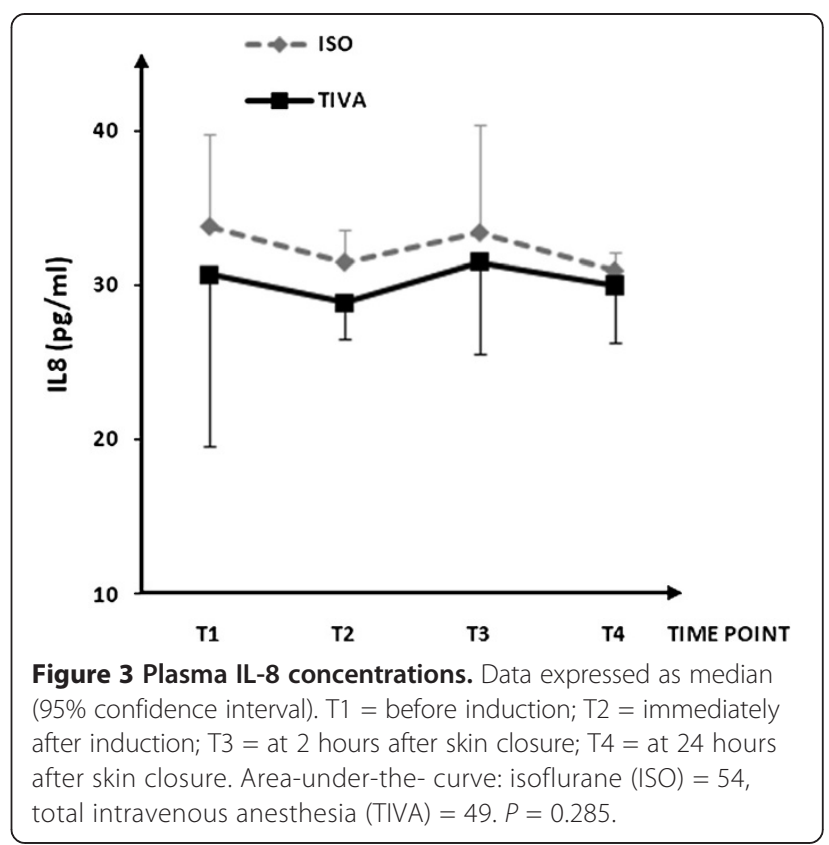

anesthesia [35]. However, they also found that IL-6 concentrations did not much differ as a function of anesthetic dose. Potential explanations include their use of regional anesthesia rather than TIVA, breast surgery rather than abdominal surgery, and the fact that all their patients had cancer, which per se can depress immune responses. Furthermore, in our study neither soluble ICAM-1 nor soluble VCAM-1 differed significantly as an effect of anesthetic technique.

A possible explanation for the results on interleukins may consist of the antioxidants and anti-inflammatory

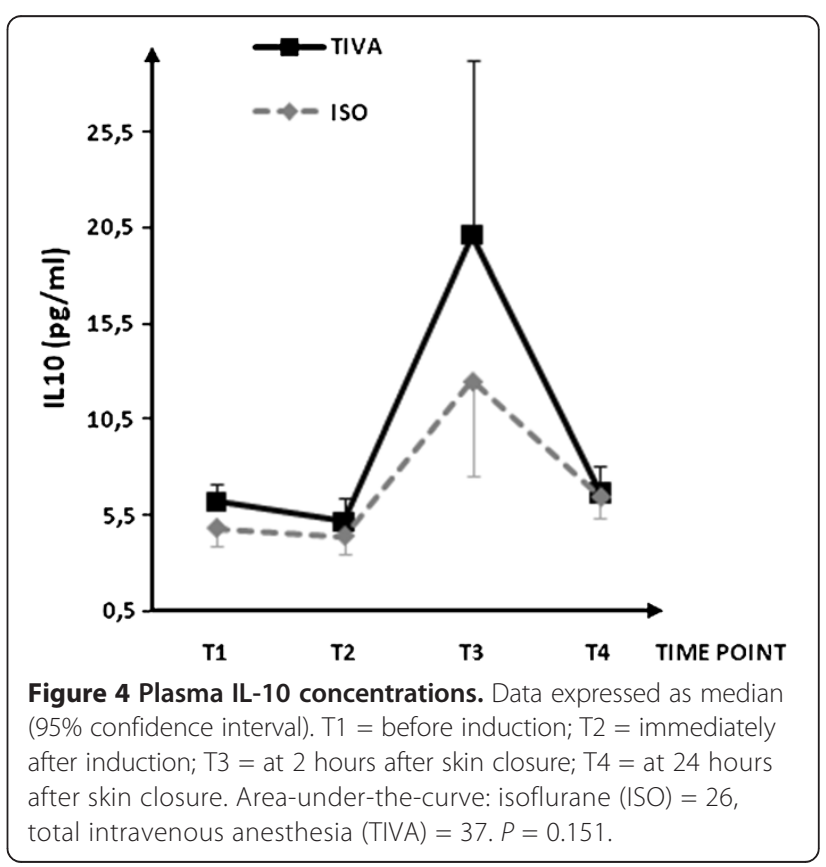




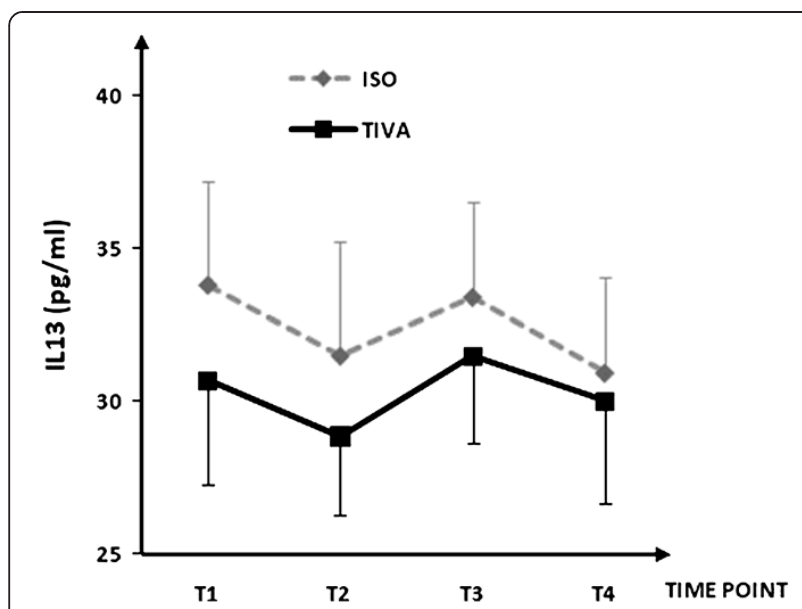

Figure 5 Plasma IL-13 concentrations. Data expressed as median ( $95 \%$ confidence interval). $\mathrm{T} 1$ = before induction; $\mathrm{T} 2=$ immediately after induction; $\mathrm{T} 3=$ at 2 hours after skin closure; $\mathrm{T} 4=$ at 24 hours after skin closure. Area-underthe- curve: isoflurane $(I S O)=101$, total intravenous anesthesia (TIVA) $=93 . P=0.218$.

effects of propofol $[24,40]$ as compared with immune effects of inhalation agents [41]. As for adhesion molecules, our results with inhalation anesthesia are similar to other studies [42], confirming that isoflurane has an inhibitory effect on CAMs. Moreover, we have demonstrated that there are no differences between inhalation anesthesia and TIVA. The anti-inflammatory effects of propofol may thus involve mechanisms other than adhesion molecules.

Directly comparing our results with previous publications is difficult since each study evaluated different

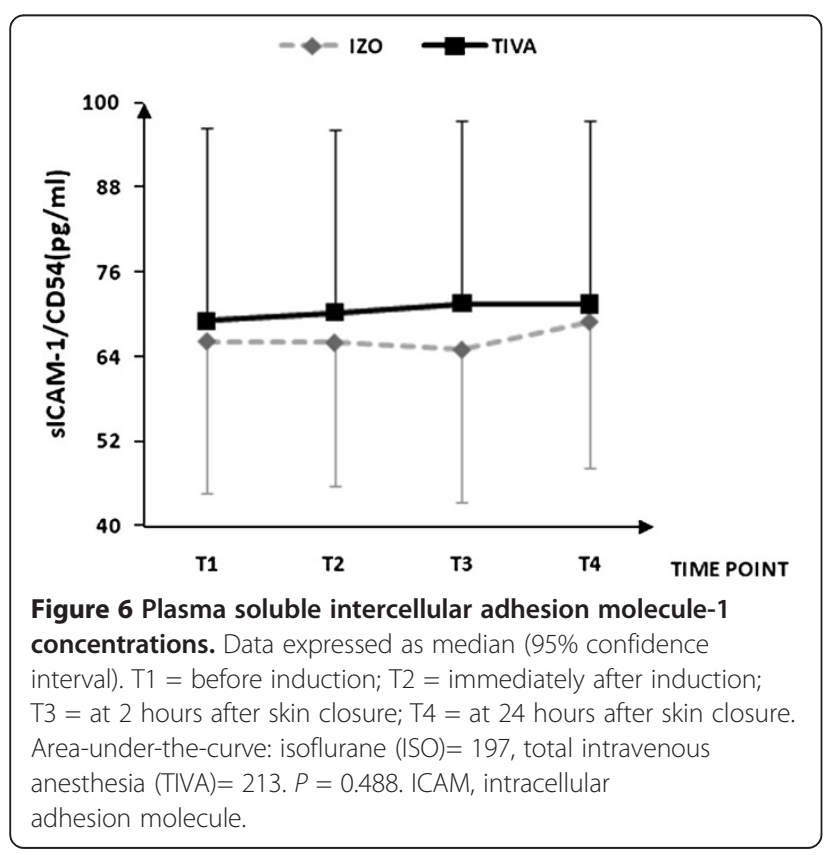

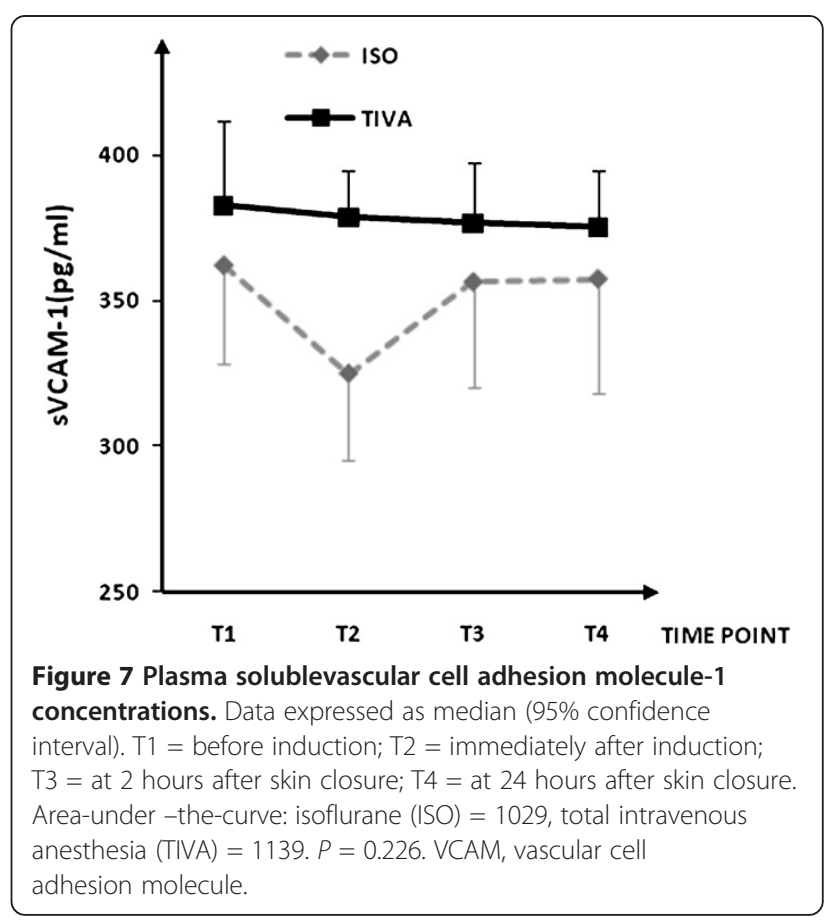

anesthetic protocols, different surgical interventions, and used different cytokine assays. Nonetheless, our results are thus generally consistent with the previous literature and are among the largest that evaluated a single typical operation.

Our study does have some limitations. A low dose of dexamethasone $(4 \mathrm{mg})$ was given to all patients for prophylaxis against postoperative nausea and vomiting, as is common in clinical practice. It is wellknown that steroids are immunosuppressive and may have ameliorated the inflammatory response to surgery. Observed differences between the randomized TIVA and volatile anesthetic groups remain valid, but it remains possible

Table 3 Area under the curve between-group comparisons

\begin{tabular}{|c|c|c|c|}
\hline & $\begin{array}{l}\text { Total intravenous } \\
\text { anesthesia }(n=44)\end{array}$ & Isoflurane $(n=44)$ & Pvalue \\
\hline IL-1ß (pg.hour/ml) & 3.4 (3.0 to 4.3$)$ & 3.3 (2.9 to 4.0$)$ & 0.428 \\
\hline IL-6 (pg·hour/ml) & 33.0 (21.6 to 44.9) & 78.0 (52.2 to 109.1$)$ & 0.006 \\
\hline IL-8 (pg·hour/ml) & 49.0 (39.6 to 67.0) & $54.0(47.2$ to 82.6$)$ & 0.285 \\
\hline IL-10 (pg·hour/ml) & 37.0 (23.8 to 55.4) & 26.0 (21.6 to 42.1$)$ & 0.151 \\
\hline IL-13 (pg·hour/ml) & $93.0(83.4$ to 101.3$)$ & $101.0(89.8$ to 112.1$)$ & 0.218 \\
\hline $\begin{array}{l}\text { Soluble ICAM-1 } \\
\text { (ng.hour/ml) }\end{array}$ & 213 (188.0 to 242.3 ) & 197 (178.9 to 220.9) & 0.488 \\
\hline $\begin{array}{l}\text { Soluble VCAM-1 } \\
\text { (ng.hour/ml) }\end{array}$ & $1,139(1,029$ to 1,188$)$ & $1,029$ (947 to 1,163$)$ & 0.226 \\
\hline
\end{tabular}

Data expressed as median (95\% confidence interval). Area-under-the-curve based on preoperative values. Mann-Whitney $U$ tests were used for betweengroup comparisons; because multiple comparisons were made, $P<0.01$ was considered statistically significant. Bold data are significant. 
that responses in both groups would be more impressive in patients not given steroids. A more serious consideration is that laparoscopic cholecystectomies produce only a moderate amount of tissue injury, and cholecystectomies presumably provoke a smaller inflammatory response than larger operations. They nonetheless well represent the types of surgery that are most commonly performed. On the contrary, having only a minor inflammatory response due to surgery, the differences may be more attributable to anesthetic technique.

Immune response is a mosaic in which interleukins and adhesion molecules are but one piece. However, it is an important piece because exaggerated or abnormally low cytokine concentrations may have a substantial effect on patient outcome. For example abnormally increased levels of IL- 6 are involved in systemic inflammatory response with impact on outcome and postoperative complications, and even on prognosis and mortality in cancer patients $[43,44]$. However, we observed relatively small differences between isoflurane anesthesia and TIVA, and only over a short period of time; whether this difference is clinically important remains unknown - but seems somewhat unlikely.

In summary, IL-6 and IL-10 increased significantly 2 hours after incision. There were no other statistically significant or clinically important perioperative increases. The only significant difference in cytokine concentrations related to anesthetic management was a greater increase in the IL-6 AUC with isoflurane anesthesia than with TIVA. However, the increase was only a factor-of -two, which is small by cytokine standards. The AUC concentrations were greater for IL-10 $(P=0.15)$, soluble ICAM-1 $(P=0.49)$, and soluble VCAM-1 $(P=0.23)$ in patients assigned to TIVA, although not significantly.

\section{Conclusion}

TIVA significantly reduced the increase in IL-6 during the perioperative period as compared with isoflurane. IL-10 and the adhesion molecules were increased, although not significantly. This effect may be favorable in some patients (for example, increased systemic inflammatory response). Further studies on larger groups of patients and for more extensive surgical interventions are needed for a better evaluation of the extent of this effect and its clinical impact.

\section{Abbreviations \\ AUC: Area under the curve; CAM: Cell adhesion molecule; Cl: Confidence interval; ELISA: Enzyme-linked immunosorbent assay; IL: Interleukin; ICAM: Intercellular adhesion molecule; NK: Natural killer; TIVA: Total intravenous anesthesia; VCAM: Vascular cell adhesion molecule.}

\section{Competing interests}

The authors declare that they have no competing interests.

\section{Authors' contributions}

$\mathrm{DCl}$ conceived the study, design study protocol, and acquisition of data, and drafted the manuscript. SCDM contributed to acquisition of data by enrolling patients and to drafting the manuscript. ANIH contributed to acquisition of data (sample preservation, storage) and the database. TNM contributed to the database and statistical analysis and interpretation of the data. NAM was responsible for immunological analysis of blood samples and interpretation. DIS revised critically the manuscript for important intellectual content and drafted parts of it. All authors read and approved the final manuscript.

\section{Funding}

This work was supported by the research grant PN 41025 funded by The National Centre for Projects Management (CNMP), Bucharest, Romania.

\section{Author details}

'Department of Anesthesia and Intensive Care I, 'Iuliu Hatieganu' University of Medicine and Pharmacy, Croitorilor, nr. 19-21, Cluj-Napoca 400162, Romania. ${ }^{2}$ Outcomes Research Consortium, Cleveland, OH, USA. ${ }^{3}$ Department of Anaesthesia and Intensive Care, Regional Institute of Gastroenterology and Hepatology'O Fodor', Croitorilor, nr. 19-21, Cluj-Napoca 400162, Romania. ${ }^{4}$ Department of Physiology, 'Iuliu Hatieganu' University of Medicine and Pharmacy, Croitorilor, nr. 19-21, Cluj-Napoca 400162, Romania. ${ }^{5}$ Department of Clinical Immunology, 'Iuliu Hatieganu' University of Medicine and Pharmacy, Croitorilor, nr. 19-21, Cluj-Napoca 400162, Romania. ${ }^{6}$ Department of Outcomes Research, The Cleveland Clinic 9500 Euclid Ave -- P77, Cleveland, $\mathrm{OH} 44195$, USA

Received: 19 November 2012 Accepted: 28 March 2013 Published: 2 May 2013

\section{References}

1. Salo M: Effects of anaesthesia and surgery on the immune response. Acta Anaesthesiol Scand 1992, 36:201-220.

2. Lin E, Calvano SE, Lowry SF: Inflammatory cytokines and cell response in surgery. Surgery 2000, 127:117-126.

3. McBride WT, Armstrong MA, Crockard AD, McMurray TJ, Rea JM: Cytokine balance and immunosuppressive changes at cardiac surgery: contrasting response between patients and isolated CPB circuits. Br J Anaesth 1995, 75:724-733

4. Breidahl AF, Hickey MJ, Stewart AG, Hayward PG, Morrison WA: The role of cellular adhesion molecules in surgery. ANZ J Surg 1995, 5:838-847.

5. McBride WT, Armstrong MA, McBride SJ: Immunomodulation: an important concept in modern anaesthesia. Anaesthesia 1996, 51:465-473.

6. Kalawski R, Bugajski P, Smielecki J, Wysocki H, Olszewski R, More R, Sheridan DJ, Siminiak T: Soluble adhesion molecules in reperfusion during coronary bypass grafting. Eur J Cardiothorac Surg 1998, 14:290-295.

7. Yukami T, Hasegawa M, Matsushita Y, Matsushita T, Horikawa M, Komura K Yanaba K, Hamaguchi Y, Nagaoka T, Ogawa F, Fujimoto M, Steeber DA, Tedder TF, Takehara K, Sato S: Endothelial selectins regulate skin wound healing in cooperation with L-selectin and ICAM-1. J Leukoc Biol 2007, 82:519-531.

8. Nagaoka T, Kaburagi Y, Hamaguchi Y, Hasegawa M, Takehara K, Steeber DA Tedder TF, Sato S: Delayed wound healing in the absence of intercellular adhesion molecule-1 or L-selectin expression. Am J Pathol 2000, 157:237-247.

9. Albelda SM: Role of integrins and other cell adhesion molecules in tumor progression and metastasis. Lab Invest 1993, 68:4-17.

10. Kobayashi H, Boelte KC, Lin PC: Endothelial cell adhesion molecules and cancer progression. Curr Med Chem 2007, 14:377-386.

11. Yang L, Froio RM, Sciuto TE, Dvorak AM, Alon R, Luscinskas FW: ICAM-1 regulates neutrophil adhesion and transcellular migration of TNF-a -activated vascular endothelium under flow. Blood 2005, 106:584-592.

12. Matheny HE, Deem TL, Cook-Mills JM: Lymphocyte migration through monolayers of endothelial cell lines involves VCAM-1 signaling via endothelial cell NADPH oxidase. J Immunol 2000, 164:6550-6559.

13. Alexiou D, Karayiannakis AJ, Syrigos KN, Zbar A, Kremmyda A, Bramis I, Tsigris C: Serum levels of E-selectin, ICAM-1 and VCAM-1 in colorectal cancer patients: correlations with clinicopathological features, patient survival and tumour surgery. Eur J Cancer 2001, 37:2392-2397.

14. Maurer CA, Friess H, Kretschmann B, Wildi S, Muller C, Graber H, Schilling M, Büchler MW: Over-expression of ICAM-1, VCAM-1 and ELAM-1 might 
influence tumor progression in colorectal cancer. Int J Cancer 1998, 79:76-81.

15. Mantur M, Snarska J, Koper O, Dziecioł J, Płonski A, Lemancewicz D: Serums ICAM, sVCAM and sE-selectin levels in colorectal cancer patients. Folia Histochem Cytobiol 2009, 47:621-625.

16. Alexiou D, Karayiannakis AJ, Syrigos KN, Zbar A, Sekara E, Michail P, Rosenberg T, Diamantis T: Clinical significance of serum levels of Eselectin, intercellular adhesion molecule-1, and vascular cell adhesion molecule-1 in gastric cancer patients. Am J Gastroenterol 2003, 98(2):478-85.

17. Ding YB, Chen GY, Xia JG, Zang XW, Yang HY, Yang L: Association of VCAM-1 overexpression with oncogenesis, tumor angiogenesis and metastasis of gastric carcinoma. World J Gastroenterol 2003, 9:1409-1414.

18. Schneemilch CE, Ittenson A, Ansorge S, Hachenberg T, Bank U: Effect of 2 anaesthetic techniques on the postoperative proinflammatory and antiinflammatory cytokine response and cellular immune function to minor surgery. J Clin Anesth 2005, 17:517-527.

19. Snyder GL, Greenberg S: Effect of anaesthetic technique and other perioperative factors on cancer recurrence. $\mathrm{Br} J$ Anaesth 2010, 105:106-115.

20. Ke JJ, Zhan J, Feng XB, Wu Y, Rao Y, Wang Y: A comparison of the effect of total intravenous anaesthesia with propofol and remifentanil and inhalational anaesthesia with isoflurane on the release of pro- and antiinflammatory cytokines in patients undergoing open cholecystectomy. Anaesth Intensive Care 2008, 36:74-78.

21. Gilliland HE, Armstrong MA, Carabine U, McMurray TJ: The choice of anaesthetic maintenance technique influences the anti-inflammatory cytokine response to abdominal surgery. Anesth Analg 1997, 85:1394-1398.

22. Crozier TA, Muller JE, Quittkat D, Sydow M, Wuttke W, Kettler D: Effect of anaesthesia on the cytokine responses to abdominal surgery. $\mathrm{Br} J$ Anaesth 1994, 72:280-285.

23. Siddiqui RA, Zerouga M, Wu M, Castillo A, Harvey K, Zaloga GP, Stillwell W: Anticancer properties of propofol-docosahexaenoate and propofoleicosapentaenoate on breast cancer cells. Breast Cancer Res 2005, 7:R645-R654.

24. Chen RM, Chen TG, Chen T-L, Lin L-L, Chang CC, Chang HC, Wu CH: Antiinflammatory and antioxidative effects of propofol on lipopolysaccharide-activated macrophages. Ann NY Acad Sci 2005, 1042:262-271.

25. Marik P: Propofol: an immunomodulating agent. Pharmacotherapy 2005, 25:28S-33S.

26. Schilling T, Kozian A, Kretzschmar M, Huth C, Welte T, Buhling F Hedenstierna G, Hachenberg T: Effects of propofol and desfluraneanaesthesia on the alveolar inflammatory response to onelung ventilation. Br J Anaesth 2007, 99:368-375.

27. Weber N, Kandler J, Schlack W, Grueber Y, Frädorf J, Preckel B: Intermitted pharmacologic pretreatment by xenon, isoflurane, nitrous oxide, and the opioid morphine prevents tumor necrosis factor $a$-induced adhesion molecule expression in human umbilical vein endothelial cells. Anesthesiology 2008, 108:199-207.

28. Corcoran TB, Engel A, Shorten GD: The influence of propofol on the expression of intercellular adhesion molecule 1 (ICAM-1) and vascular cell adhesion molecule 1 (VCAM-1) in reoxygenated human umbilical vein endothelial cells. Eur J Anaesthesiol 2006, 23:942-947.

29. Apfel CC, Korttila K, Abdalla M, Kerger H, Turan A, Vedder I, Zernak C, Danner K, Jokela R, Pocock SJ, Trenkler S, Kredel M, Biedler A, Sessler DI, Roewer N, IMPACT Investigators: A factorial trial of six interventions for the prevention of postoperative nausea and vomiting. N Engl J Med 2004, 350:2441-251

30. Sessler DI: Long-term consequences of anaesthetic management. Anesthesiology 2009, 111:1-4.

31. Kurz A, Sessler DI, Lenhardt RA: Study of wound infections and temperature group: perioperative normothermia to reduce the incidence of surgical-wound infection and shorten hospitalization. $N$ Engl J Med 1996, 334:1209-1215.

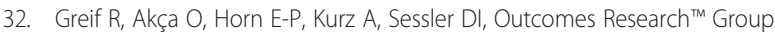
Supplemental perioperative oxygen to reduce the incidence of surgical wound infection. N Engl J Med 2000, 342:161-167.

33. POISE Study Group, Devereaux PJ, Yang H, Yusuf S, Guyatt G, Leslie K, Villar JC, Xavier D, Chrolavicius S, Greenspan L, Pogue J, Pais P, Liu L, Xu S, Málaga G, Avezum A, Chan M, Montori VM, Jacka M, Choi P: Effects of extendedrelease metoprolol succinate in patients undergoing non-cardiac surgery (POISE trial): a randomised controlled trial. Lancet 2008, 371:1839-1847.
34. Perouansky M, Hemmings HC: Between Clotho and Lachesis: how isoflurane seals neuronal fate. Anesthesiology 2009, 110:709-711.

35. Deegan CA, Murray D, Doran P, Moriarty DC, Sessler DI, Mascha E, Kavanagh $B P$, Buggy DJ: Anaesthetic technique and the cytokine and matrix metalloproteinase response to primary breast cancer surgery. Reg Anesth Pain Med 2010, 35:490-495.

36. Exadaktylos AK, Buggy DJ, Moriarty DC, Mascha E, Sessler DI: Can anaesthetic technique for primary breast cancer surgery affect recurrence or metastasis? Anesthesiology 2006, 105:660-664.

37. Gottschalk A, Sharma S, Ford J, Durieux M, Tiouririne M: The role of the perioperative period in recurrence after cancer surgery. Anesth Analg 2010, 110:1636-1643.

38. Monk TG, Weldon BC: Anaesthetic depth is a predictor of mortality: it's time to take the next step. Anesthesiology 2010, 112:1070-1072.

39. Helmy SAK, Wahby MAM, El-Nawaway M: The effect of anaesthesia and surgery on plasma cytokine production. Anaesthesia 1999, 54:733-738.

40. Corcoran TB, Engel A, Sakamoto H, O'Shea A, O'Callaghan-Enright S, Shorten GD: The effects of propofol on neutrophil function, lipid peroxidation and inflammatory response during elective coronary artery bypass grafting in patients with impaired ventricular function. Br J Anaesth 2006, 97:825-831.

41. Inada T, Yamanouchi Y, Jomura S, Sakamoto S, Takahashi M, Kambara T, Shingu K: Effect of propofol and isofluraneanaesthesia on the immune response to surgery. Anaesthesia 2004, 59:954-959.

42. Yuki K, Astrof NS, Bracken C, Yoo R, Silkworth W, Soriano SG, Shimaoka M: The volatile anaestheticisoflurane perturbs conformational activation of integrin LFA-1 by binding to the allosteric regulatory cavity. FASEB $J$ 2008, 22:4109-4116.

43. Knüpfer $H$, Preiss R: Significance of interleukin-6 (IL-6) in breast cancer [review]. Breast Cancer Res Treat 2007, 102:129-135.

44. Nicolini A, Carpi A, Rossi G: Cytokines in breast cancer. Cytokine Growth Factor Rev 2006, 17:325-337.

doi:10.1186/2047-0525-2-8

Cite this article as: lonescu et al:: Choice of anesthetic technique on plasma concentrations of interleukins and cell adhesion molecules. Perioperative Medicine 2013 2:8.

\section{Submit your next manuscript to BioMed Central and take full advantage of:}

- Convenient online submission

- Thorough peer review

- No space constraints or color figure charges

- Immediate publication on acceptance

- Inclusion in PubMed, CAS, Scopus and Google Scholar

- Research which is freely available for redistribution

Submit your manuscript at www.biomedcentral.com/submit
C) Biomed Central 